HEED

15,1

2

Received 27 October 2020 Revised 8 January 2021 Accepted 9 January 2021

\section{No road is long with good company. What factors affect Ph.D. student's satisfaction with their supervisor?}

\author{
Marco Seeber \\ University of Agder, Kristiansand, Norway, and \\ Hugo Horta \\ Social Contexts and Policies of Education, University of Hong Kong, \\ Hong Kong, Hong Kong
}

\begin{abstract}
Purpose - How frequently may be advisable for a supervisor to meet a PhD student? Are PhD students more satisfied if supervised by someone of the same gender, nationality or with common research interests? Thus far, we lack quantitative evidence regarding similar crucial aspects of managing $\mathrm{PhD}$ supervision. The goal of this study is hence to investigate what factors affect Ph.D. students' satisfaction about the professional and personal relationships with their supervisors.

Design/methodology/approach - We focus on the characteristics of the interactions between the student and the supervisor, controlling for other important factors, namely, the supervisor's and student's traits, and the characteristics of the context. We employ survey responses from $971 \mathrm{Ph}$.D. students at two public, researchoriented and internationally renowned universities in Hong Kong and South Korea.

Findings - The results show the importance of meeting the supervisor at least once per week. Students are more satisfied of the relationship with their supervisor when they have similar research interests, whereas a key finding is that similarity in terms of gender or nationality does not matter. We also found remarkable differences between disciplines in the level of satisfaction (up to 30\%), and that students are more satisfied when the supervisor is strongly involved in international research, whereas satisfaction is negatively affected by the number of $\mathrm{Ph} . \mathrm{D}$. students supervised.

Originality/value - The article's findings suggest that students are not more satisfied of their relationship with their supervisors when they have the same gender or nationality, whereas it is other traits of their interaction, such as the frequency of meetings and the similarity of research interest, which matter.
\end{abstract}

Keywords Gender, Homophily, Student satisfaction, Doctoral education, $\mathrm{PhD}$ supervision,

Student supervisor interaction

Paper type Research paper

\section{Introduction}

The massification of higher education is increasingly being extended to doctoral studies. There are growing numbers of Ph.D. students in universities worldwide, as more students holding bachelor and master's degrees opt to continue their education at doctoral level (Pásztor and Wakeling, 2018). Doctoral studies have changed over the past decades, as individual, policy-driven, organisational and national incentives have combined to stimulate participation by a more heterogeneous population of students (Pearson et al., 2008; Cyranoski et al., 2011; Gould, 2015). Doctoral programmes currently cater to a diverse body of students with a wide range of reasons for doing a Ph.D. and who have a wider range of possible

(C) Marco Seeber and Hugo Horta. Both authors contributed equally to the development of the article. Published in Higher Education Evaluation and Development. Published by Emerald Publishing Limited. This article is published under the Creative Commons Attribution (CC BY 4.0) licence. Anyone may reproduce, distribute, translate and create derivative works of this article (for both commercial and noncommercial purposes), subject to full attribution to the original publication and authors. The full terms of this licence may be seen at http://creativecommons.org/licences/by/4.0/legalcode
Higher Education Evaluation and Development

Vol. 15 No. 1, 2021

pp. $2-18$

Emerald Publishing Limited

2514-5789

DOI 10.1108/HEED-10-2020-0044 
professional paths after obtaining the degree (Roach and Sauermann, 2017; Manathunga et al., 2009).

Despite the changes to doctoral education, a critically important issue in doctoral studies is the relationship between a student and the supervisor (Mainhard et al., 2009). Ph.D. students tend to rely on supervisory collaboration, guidance and support for both publications and career advice (Jung et al., 2021; Gu et al., 2018). The knowledge produced during the doctorate is associated with the student's developmental capacity (Mowbray and Halse, 2010), which also largely depends on the supervisor-supervisee personal and professional relationship (Bastalich, 2017; Wisker, 2005). The quality of the relationship with the supervisor also importantly affect dropping out and completion time (Vassil and Solvak, 2012). However, recent research has found that Ph.D. students suffer from high levels of stress and anxiety (Levecque et al., 2017), in part due to the programmatic and signalling requirements placed on them, including the need to publish and be visible during their doctoral studies (Horta and Santos, 2016).

A plethora of studies have focused on supervision in doctoral studies, yet three main gaps can be identified. First, almost all of them have been based on qualitative research methodologies. These studies have provided important exploratory and in-depth understandings of specific issues pertaining to satisfaction, but confirmatory studies, that is, studies using quantitative methods, are needed to complement current findings. Second, most studies have focused on supervisors' experiences, practices and roles to benchmark good practices for other supervisors (e.g. Benmore, 2016; Lee, 2008). However, as universities focus on student-centred learning, it is increasingly important to understand the perspectives of the students (McAlpine et al., 2012). Third, existing studies have overwhelmingly focused on higher education systems in North America, Europe and Oceania, with few focusing on doctoral education and supervision in other parts of the world. This is a glaring deficit, given that doctoral education has increased substantially everywhere, and particularly in East Asia (Shen et al., 2018).

Given the crucial importance of Ph.D. students' satisfaction with their supervision, this study explores what factors predict Ph.D. students' satisfaction with both the professional and personal relationship with their supervisor. It uses quantitative data, specifically survey information provided by $\mathrm{Ph}$.D. students at two public, research-oriented and internationally renowned universities in Hong Kong and South Korea. These two universities are used as reference cases for other East Asian universities in terms of doctoral education, as both are leaders in the production of $\mathrm{PhDs}$ in their respective jurisdictions and represent institutional role models for other universities.

The article is structured as follows. In the next section, we review research on doctoral supervision to identify what factors can predict satisfaction, along the supervisor's and student's traits, and the characteristics of the context. Next, we develop hypotheses specifically on some key traits of the interaction between the student and the supervisor: the frequency of their meetings, as well as their similarity in terms of research interests, gender and nationality. This is followed by the methods section, and the results section. The article concludes with a discussion of the findings and their managerial and policy implications.

\section{Student relationship with the supervisor and the factors affecting its quality}

Several studies have highlighted the importance of the supervisor-supervisee relationship to the success of a Ph.D. (e.g. Mainhard et al., 2009; McAlpine and Norton, 2006; Golde, 2000). Studies performed in the 1980s and 1990s established the importance of both the personal relationship and the professional relationship as keys to a successful supervision (e.g. Hockey, 1996).
Ph.D. student's satisfaction with supervisors 
HEED

15,1

4

Good interpersonal relationships have been consistently found to be associated with both $\mathrm{Ph} . D$. student satisfaction and good progress in doctoral studies (e.g. Ives and Rowley, 2005), while conflicts are negatively correlated with success (e.g. McAlpine et al., 2012). Situated within the broader environment and space where doctoral education takes place, supervisorsupervisee relationships is thus the strongest determinant of a positive doctoral learning experience for Ph.D. students (e.g. Zhao et al., 2007), pivotal for the competency building capacity of the student, as well to the production of new knowledge throughout the Ph.D. programme (Jung, 2018; Bastalich, 2017; McAlpine and Norton, 2006) [1].

In turn, both parties in this relationship are interested in a positive doctoral journey, although studies have shown that goals and objectives are not always aligned, and tensions are bound to emerge (Shibayama, 2019). In other words, the quality of the relationship between a student and her/his supervisor is not dependent uniquely on the characteristics or efforts - of either the student or the supervisor only. Arguably, this depends both on the traits of the supervisor and of the student, the context in which they are embedded, and the interactions through which they can develop a relationship. In the following sub-sections, we review some major insights from past research on the importance of the characteristics of the supervisor, the student and the context. Then, we focus on the interaction between the student and the supervisor, and develop hypotheses on how specific traits of their interactions supposedly impact students' satisfaction with their supervisor.

\subsection{Supervisor's traits}

Doctoral students are the ones most responsible for their own learning, work development and goals. At the same time, supervisors are expected to guide them through a complex learning process and to support them through the emotional roller coaster that doctoral studies can become, as students may experience periods of procrastination, self-doubt and anxiety (McAlpine et al., 2012). Supervisors also provide expertise and time to ensure that a student's research competencies are developed, and that the student is properly socialised in the ways of doing research and in producing new knowledge within a field community (Heath, 2002). More recently, doctoral students have also started to seek advice on possible post-doctoral career paths from their supervisors (Gu et al., 2018). In turn, supervisors with more research expertise and broader research networks are expected to better cope with such needs, positively affecting students' satisfaction of the professional relationship with the supervisor.

Shin et al. (2018) found that the number of Ph.D. students that the supervisor mentors is not associated with satisfaction with the overall $\mathrm{Ph}$.D. programme. On the other hand, having to supervise large number of students arguably reduce both the number of meetings one can have with students and/or the time available for each meeting. Hence, if we assume that time is necessary to develop a good relationship, we can expect that the number of students supervised negatively affect the satisfaction with the professional relationship.

Possibly, demographic traits of the supervisor like the age and the gender, as well as her academic rank may be associated with the students' satisfaction with their relationship, although the importance of these variables has not been explored so far.

\subsection{Student's traits}

It can be argued that doing a $\mathrm{PhD}$ requires specific traits. Recent research by Zhang et al. (2018) has shown that the thinking styles - namely type I, associated with a preference for creative and complex cognitive tasks, and type II, associated with a preference for tasks favouring following norms and requiring lower levels of cognitive complexity (Sternberg et al., 2007) - of Ph.D. students in science, technology, engineering and mathematics affect their satisfaction with the doctoral programme curricula, peer interactions, their perceptions 
of institutional support and their perception of their own intellectual competence. In a similar vein, Ph.D. students' satisfaction of the personal and professional relationship with their supervisors may also be affected by their preferred ways of learning. This is consistent with qualitative findings that relate Ph.D. students' notions of a "good supervisor" to their own thinking styles (Halbert, 2015).

Other characteristics of the Ph.D. students may also affect satisfaction with their supervision such as gender, age, nationality, their parents' level of education and having children or not. No study has quantitatively measured the role of these sociodemographic elements in doctoral students' satisfaction with supervision, although qualitative studies have suggested they play a role. For example, concerning gender, Carter et al. (2013) stress that identity transformation during the Ph.D. is more difficult for women than for men due to women's role in family nurturance and symbolic subordination to male supervisory authority. In general, qualitative research on the effect on gender and family on satisfaction levels has produced mixed findings: Kurtz-Costes et al. (2006) find that female Ph.D. students value female supervisors even if they are less supportive of family concerns than male supervisors, whereas Brown and Watson (2010) find no influence of gender on the supervisory relationship.

\subsection{Context}

The context in which a relationship develops can be very important for its quality. Most prominently in our case, the scientific disciplines in which a $\mathrm{PhD}$ occur are expected to have strong influence. Part of the effect of the discipline is indirect and considered by other variables such as the number of students per supervisor, as these may be higher in some fields than others, or the frequency of meetings. Other aspects are more subtle. For example, supervision implies a socialisation of the student into a specific field community (Lee, 2008), and disciplines differ greatly in term of beliefs, formal and informal rules (Clark, 1983), as well as the extent to which they are internally cohesive and hierarchical (Whitley, 2000). How work is organized - from laboratory, to more one-to-one interactions - and publication practices, collective or more individual, can strongly affect what are the expected role of the student and the supervisor, the kind of interaction they have, and in turn the quality of the personal and professional relationship.

Differences in satisfaction can also exist across countries and universities, due to variations in the formal and informal institutions, or amount of available resources.

\subsection{Student-supervisor interactions}

The literature reveals that the supervisor-supervisee relationship is a process that involves negotiation, the scholarly exchange of ideas and the ability to reach consensus on the best way to develop research directions during the doctoral journey. In this respect, a central debate regards how frequently should the student and supervisor meet. A Ph.D. student is expected to be relatively independent and/or evolve from relative dependence on a supervisor to becoming an autonomous researcher, gradually socialised to be a member of academia (Baker et al., 2013). To cope with this transition, the supervisor is required to develop good professional and personal relationships with the student, giving adequate and timely support. On the other side, this should not turn into "spoon feeding" or "over directing" the research (Holligan, 2005), which create dependence (Deuchar, 2008). Hockey (1996) and more recently Benmore (2016) have discussed the importance of establishing boundaries, arguing that supervisors should avoid "over involvement" for two reasons: (1) to allow Ph.D. students to demonstrate their ability to work largely on their own, which guarantees the students' autonomy, originality and creativity and intellectual potential and paves the way for them to become independent researchers, 
HEED

15,1

and (2) to avoid over-influencing the students or doing the thinking for them (Lindsay, 2015; Hockey, 1994).

The number of interactions between a student and a supervisor can represent a proxy for supervisory approaches that range from "hands-on" to "hands-off" approaches (more freedom and responsibility given to the student vs more structuring and top-down guidance), while balance and variability are arguably desirable (McCallin and Nayar, 2012). Despite the expectations that students will become less reliant on the supervisor over the programme, studies of doctoral education underline the importance of frequent supervisor-supervisee meetings throughout the entire doctoral programme (particularly after the coursework is concluded), as the frequency of meetings positively affect the completion of the doctorate as well as the quality of research (Barnes and Austin, 2009; Li and Seale, 2007; Shin et al., 2018). Therefore, we formulate the hypothesis that:

H1. Students that meet their supervisor more frequently are more satisfied about their relationship with them

While the previous paragraphs discussed the potential impact respectively of the supervisor's and the student's traits, the interaction between their respective traits also likely affects the quality of their relationship. One important debate concerns whether student and supervisor should possess similar socio-demographic characteristics.

Experimental research from social psychology provides interesting insights about the matching between learner's and teacher's traits, and how this matching can affect their relationship. Humans are skilled adaptive learners who, whenever possible, carefully select what and with whom to learn. To do that, humans use cues that allow them to target those people most likely to possess information that will increase the learner's survival and reproduction (Henrich, 2017). Along with cues of skills, competence and prestige, people also use, unconsciously, cues of self-similarity, like gender and ethnicity. Self-similarity cues help learners to focus on those people most likely to possess the social norms, symbols, and practices that they will need for a successful social life (Henrich, 2017). In sum, there is established evidence that both children and adults prefer to interact with, and learn from, same-gender models. Research on ethnicity biases in cultural learning is more limited, but points to a similar direction, for example toward a preference for people speaking the same language, dialect, and sharing some of their beliefs.

However, empirical research in real settings provides contrasting results in this regard. On the one hand, studies observed that mentees in same-gender dyads received more psychosocial support than mentees in cross-gender dyads (Koberg et al., 1998). In a similar vein, Carter et al. (2013) and Kurtz-Costes et al. (2006) argue that female Ph.D. students are more comfortable with and value more female supervisors. Teachers may also have similar preferences, leading them to preferentially assist or reward those who share their gender or ethnic markers (e.g. Kinzler et al., 2011). Recent studies indicate that intercultural tensions can make it difficult for non-national supervisees to adapt to personal and professional relationships with their supervisors (Kidman et al., 2017). Having a supervisor from the same country can mitigate or annul feelings such as "othering", particularly for international Ph.D. students (Laufer and Gorup, 2019). On the other hand, some studies such as the one by Sosik and Godshalk (2000) found that cross-gender mentoring relationships provided higher levels of role modelling, and that mentees in cross-gender mentoring dyads reported receiving greater amounts of psychosocial support from their mentors (Sosik and Godshalk 2005). The authors argued that this may be due to potential complementarity in cross-gender mentoring relationships (also suggested by Kram, 1986).

In the context of these contrasting evidences, we test the homophily mechanism thesis with the following hypotheses: 
H2a. Students will be more satisfied of their supervisor when they have the same gender

$H 2 b$. Students will be more satisfied of their supervisor when they have the same nationality

An alternative argument to the gender-ethnicity similarity hypothesis- is that for adults involved in a long-term learning relationship, other dimensions of similarity may be more important. In the case of $\mathrm{Ph} . \mathrm{D}$. supervision relationship, a primary element that student and supervisor are expected to share is a common research interest namely on the doctoral research topic, which in many cases happens naturally at the start of the Ph.D. programmes (Ives and Rowley, 2005). Hence, we formulate the hypothesis that:

H3. Students will be more satisfied when they have chosen a supervisor with similar research interest

\section{Data and methods}

\subsection{Data}

Data for this study were collected from a survey administrated throughout 2016 to doctoral students at two large East Asian universities, one located in Hong Kong and the other in South Korea. Both are public, research-oriented, flagship universities that are consistently rated in the top positions of various world university rankings. They are well-integrated into global research networks and their doctoral education programmes have similar structures. The first years are focused on coursework and the subsequent years are focused on research. In both universities the students have a main supervisor that guides them through the doctoral journey. In both cases, students are expected to be engaged in administrative and research work of the supervisor's research project(s), mostly rely on funding from national or institutional sources to support their studies, conceive their PhDs mostly as a research project conductive to the delivery of a product (i.e. thesis), and eventually can have a teaching experience by serving as teaching assistants in courses led by the supervisors (Torka, 2018). In a broad sense, this is like the generality of doctoral experiences in most developed countries. The differences between the doctoral education at these two universities are mostly related to institutional and national characteristics. The university based in Hong Kong has greater proportions of non-national academic staff and students, is more internationalized in its focus, and always has English as a medium of instruction (as is typical of Hong Kong university settings; see Kwan, 2013).

The questionnaire administered to the Ph.D. students was developed and tested by an international team, as this research is part of a larger international collaborative project (Shin et al., 2015). The aim of the project was to better understand who the $\mathrm{PhD}$ students at these universities were, and comprehend their learning experiences, understandings and perceptions about competences learned during their doctoral studies. Although the questionnaire was focused on a broad set of questions, several of the questions asked had this study in mind when the questionnaire was designed. The Ph.D. students responded to questions about several aspects of their doctoral programme and experience, including admission and supervisor selection, satisfaction, learning and research activities, thinking styles, career plans and demographic information. Most of the survey questions asked the Ph.D. students to rate their agreement with statements using a Likert scale from 1 (not at all) to 7 (extremely true). A smaller share of questions required a yes/no response (e.g. do you have a supervisor?), a nominal response (e.g. what is the academic rank of your supervisor?) or the provision of specific information (e.g. how many doctoral students does your core supervisor have?). Fewer questions required the respondents to provide more detailed information in their responses.
Ph.D. student's
satisfaction
with
supervisors 
HEED

15,1

After ethical approval, the questionnaires were distributed in person to the $\mathrm{Ph}$.D. students at both universities. This was a lengthy process that took several months during 2016 . The respondents were given information about the purpose and content of the survey, including the voluntary nature of their participation, and they consented to the terms and conditions of participating in the survey. The respondents were given a guarantee of anonymity. A cluster sample strategy was followed based on the number of doctoral students in each faculty, which permitted the samples to have a degree of representativeness of the Ph.D. populations in both universities. The final sample included 994 Ph.D. students (509 from the Korean university case, 485 from the Hong Kong university case), who had completed a full version of the questionnaire.

The sample used in the analysis consisted of 971 Ph.D. students who were full-time Ph.D. students (96.1\% of the respondents). Full-time Ph.D. students were made the focus because their supervisory experiences ought to be more homogenous than those of part-time students. Furthermore, the commitment and availability of part-time students differs substantially from that of full-time students (Gardner and Gopaul, 2012). The average age of the respondents was 31 years old, $46 \%$ were woman, $11 \%$ had children, and $19 \%$ were nonnational. $24 \%$ were in their first year, $25 \%$ in their second year, $21 \%$ in their third year, $19 \%$ in their fourth year, $6 \%$ in their fifth year and $5 \%$ in their sixth year. The most represented academic disciplines were engineering $(24 \%)$, natural sciences $(22 \%)$, social sciences $(15 \%)$, education $(12 \%)$, medicine $(9 \%)$ and humanities $(9 \%)$. Only $12 \%$ of the Ph.D. students had both a mother and father with a low educational background (i.e. below high school), whereas $62 \%$ had at least one parent with a college or graduate degree. Most of the Ph.D. students benefited from scholarships $(61 \%$ at the Korean university and $89 \%$ at the Hong Kong university).

\subsection{Variables}

3.2.1 Dependent variables. The dependent variables are derived from two specific questions about the Ph.D. students' relationships with their supervisors: (1) I have a good professional relationship with my supervisor and (2) I have a good personal relationship with my supervisor. The responses use a Likert scale from 1 (not at all) to 7 (extremely true), with equal intervals, and are treated as continuous (Norman, 2010).

3.2.2 Predicting variables. The independent variables pertain to $\mathrm{Ph} . \mathrm{D}$. student-supervisor interaction:

Frequency of meetings (hypothesis 1). How often does the Ph.D. student meet the supervisor: (1) every day (2) several times a week; (3) once a week; (4) once in two weeks; (5) once a month and (6) once a semester.

Same gender (hypothesis 2a). This variable indicates the gender matching studentssupervisor, either female-female, female-male, male-female, male-male.

Same nationality (hypothesis $2 b$ ). The variable measures whether the $\mathrm{Ph} . \mathrm{D}$. student and the supervisor have the same nationality [2].

Choice of supervisor - similar research interest (hypothesis 3). In a section dedicated to the factors which were important in the selection of their supervisor, the student rated their level of agreement with the statement "My interest and my supervisor's research interest are similar" (scale 1-7, whereas 7 means maximum similarity between the research interests of the supervisee and the supervisor).

3.2.3 Control variables. Other control variables pertain to the (1) supervisor traits, (2) Ph.D. student traits, as well as the (3) characteristics of the context and the (4) further characteristics of the interaction between the student and the supervisor.

3.2.3.1 Characteristics of the supervisor. Supervisor involvement in research. Three questions in the survey assess the supervisor's involvement in research activity: (1) regularly 
publishes articles in international journals; (2) regularly attends international conferences and (3) has a strong international research network. A factor analysis of the answers to these three questions produces a single factor explaining $76.4 \%$ of the variance; this factor is used as a predictive variable.

Number of Ph.D. students supervised. This discrete variable counts the number of Ph.D. students a supervisor is supervising at the time of the administration of the questionnaire.

Academic rank. Three possible ranks are considered: (1) assistant professor; (2) associate professor and (3) professor.

Supervisor gender. Dummy variable: male/female.

Supervisor age at the time of the survey.

3.2.3.2 Characteristics of the Ph.D. student. Thinking styles. The survey includes 30 items on six thinking styles [3] assessed on a 7-points Likert scale, including three Type I styles and three Type II styles (see Thinking Styles Inventory Revised II TSI-R2, Zhang et al., 2018; and Sternberg et al., 2007). The three Type I thinking styles are (1) legislative, which is a preference for tasks that require creative strategies, (2) liberal, which is a preference for tasks that involve novelty and ambiguity and (3) hierarchical, which is a preference for distributing attention across tasks with a sense of priority. The three Type II thinking styles are (1) executive, which is a preference for implementing tasks based on clear guidelines; (2) conservative, which is a preference for carrying out tasks according to existing rules and procedures and (3) monarchic, which is a preference for tasks that allow complete focus on one issue at a time. The use of thinking styles to generally characterise Ph.D. students (as those preferring to do work with higher levels of independence and creativity versus those who prefer a more guided, rule-based work structure) may help to understand if Ph.D. students with different learning preferences experience differing levels of supervisory satisfaction.

Previous studies using the TSI-R2 indicate that all the scales have satisfactory internal scale reliabilities (e.g. Fan and Zhang, 2014) and are valid for assessing thinking styles in a wide range of populations (see Zhang et al., 2018). The internal structure of the TSI-R2 is examined via confirmatory factor analysis and principal component analysis, using SPSS. Initially, six factors are identified (eigenvalues greater than 1; Kaiser, 1960; 60.9\% of variance absorbed). Items related to the legislative and liberal thinking styles load on to the first factor, conservative and executive style items load on to the second factor and hierarchical style items load on to the third factor. However, the monarchic style items are split between the fourth and fifth factor, and no item loads strongly on the sixth factor. Eigenvalues for the fifth and sixth factors are also borderline to the threshold of 1 (i.e. 1.07 and 1.03, respectively) Therefore, a four-factor solution is selected $(53.9 \%$ variance absorbed). In this case, the monarchic style items clearly load on the fourth factor (eigenvalue 1.62).

Ph.D. student gender. Dummy variable: male/female.

Academic year. The year in which the Ph.D. student is enrolled.

Children. Whether the Ph.D. student has child/children or not.

Ph.D. student age at the time of the survey.

3.2.3.3 Context. Academic discipline. Ph.D. experience and work vary across disciplines. We therefore explore whether students' satisfaction with supervision varies across the 11 disciplinary affiliations identified in the survey: humanities; social sciences; engineering; natural sciences; medicine; arts and sports; education; business; architecture; computing and other.

University of affiliation. A dummy variable is used to indicate the university where the Ph.D. student is currently doing a doctorate. The university is anonymised for confidentiality.
Ph.D. student's satisfaction with supervisors 
HEED

15,1

3.2.3.4 Ph.D. student-supervisor interaction (further controls). Choice of supervisor undergraduate supervisor. The extent to which a student selected a Ph.D. supervisor because he/she was supervised by the same supervisor in a previous degree (scale 17 , whereas 7 mean that this selection is mostly explained by the fact that the student was supervised before by the same supervisor). Allowing Ph.D. students to choose supervisors based on previous educational experience - like a previous experience of supervision at undergraduate level - has been proposed as a solution to improve the quality of the supervision (Gurr, 2001), although both heterogeneous and homogeneous supervisor-supervisee team-ups have been shown to bring benefits (see Ooms et al., 2019).

3.2.3.5 Additional variables were also controlled for [4]. Scholarship. The extent to which the Ph.D. student is supported by a scholarship (0-100\%), as the literature suggests that a funded $\mathrm{Ph}$.D. is likely to produce better outcomes and to be more stable (Horta et al., 2019). It is also expected to have implications for the student's satisfaction with the supervisory experience (see Maloshonok and Terentev, 2019).

International Ph.D. student. Whether the Ph.D. student is a national or non-national citizen. This variable is important, because a non-national Ph.D. student may perceive him or herself as being marked as different due to a lack of familiarity with the institutional identity and culture, societal culture, language or other elements critical for integration. Laufer and Gorup (2019) call this process "othering".

Parents' educational level. The survey contains two separate questions on a student's mother's and father's highest level of completed education. The scales are the same for both questions: (1) no education; (2) primary school; (3) middle school; (4) high school; (5) 2-years college; (6) 4-years college and (7) graduate education. Parents' educational levels are highly correlated $(0.72 p$-value $<0.01)$, and a factor analysis identifies one factor $(86 \%$ of the variance) that is used as the predicting variable.

\subsection{Methods}

The empirical analysis uses both descriptive and inferential statistics to identify the factors that predict Ph.D. students' satisfaction with their professional and personal relationships with their supervisors. It first explores the possibility of significant differences using descriptive evidence, including non-parametric tests and correlation analysis. Next, two sets of linear regression models are run separately for the two dependent variables. Each set includes four regressions models, that progressively add variables expressive of the (1) context; (2) supervisor characteristics; (3) student characteristics and (4) student-supervisor interaction characteristics [5]. Multicollinearity is not a major concern in our regression models, because the highest Generalised collinearity diagnostic (G-VIF-variance inflation factor) is 3.42 (highest $\mathrm{GVIF}^{\wedge}(1 /(2 * \mathrm{Df})$ of 1.47$)$, well below the critical cut-off value of $10 . \mathrm{A}$ robust test is run including only Ph.D. students in the first and second years of the academic programme, in order to: (1) determine whether the results are different for Ph.D. students engaged in coursework, and (2) to rule out the possibility that the significance of certain variables is due to endogenous relationships between the dependent and the predictive variables [6].

\section{Analysis}

\subsection{Descriptive analysis}

On average, Ph.D. students in our sample are fairly satisfied with the professional relationship with their supervisor (mean 5.17) and somehow satisfied with the personal relationship with their supervisor (4.56) [7]. The two dimensions of supervision satisfaction 
are strongly correlated with each other $(0.52 p$-value $<0.01)$, but not sufficiently correlated with one another to suggest they should be merged in one variable.

The supervisor's level of involvement in international research is significantly associated with satisfaction with both professional $(0.12, p$-value $<0.001)$ and personal relationships $(0.09, p$-value 0.004$)$. The gender, age and academic rank of the supervisor and the number of Ph.D. students supervised do not relate to meaningful differences in Ph.D. students' satisfaction with supervision.

Male and female Ph.D. students display very similar levels of satisfaction, respectively, 5.14 vs 5.20 for the professional relationship and 4.57 vs 4.54 for the personal relationship. The differences are not statistically significant (Mann-Whitney non-parametric tests $p$-value 0.26 and 0.93). No significant differences exist between students in different academic years. $\mathrm{Ph}$.D. students with stronger type I thinking styles (TS) express higher satisfaction with both professional and personal relationships (legislative TS 0.24 and liberal TS 0.19, $p$-value $<0.001$ and hierarchical TS, $0.23 ; p$-value $<0.001$ and $0.09 ; p$-value 0.008$)$. In contrast, no association is observed between satisfaction and type II TS, except a weak association between monarchic TS and professional relationship satisfaction $(0.08$; $p$-value 0.009).

Ph.D. students for some academic disciplines experience better professional relationships than others (e.g. the mean in education is $5.29 \mathrm{vs}$ natural science 5.11 ). This is also true for personal relationships (e.g. medicine 4.66 vs engineering 4.51 ).

$\mathrm{Ph} . \mathrm{D}$. students that meet their supervisor every day or several times a week are more satisfied than students who meet their supervisor once a week, every two weeks or once a month. They are much more satisfied than the relatively few students who only met their supervisor once a semester (Table 1).

Clearly, a multivariate analysis is warranted to disentangle the effect of each variable.

\subsection{Regression analysis}

Table 2 present the results of the two linear regression models predicting, respectively, Ph.D. students' professional and personal satisfaction with their supervisors.

The results for the professional relationship show that meeting with a supervisor several days a week, once a week and every day have similar impact on satisfaction. On the other hand, Ph.D. students who meet once every two weeks or once in a month are significantly less satisfied than those meeting every day $(-6.6$ and $-7.5 \%)$, and those meeting only once in a semester are much less satisfied $(-23.5 \%$ ) (Hypothesis 1$)$. Students whose supervisor have the same gender or nationality are not significantly more satisfied, which confute Hypotheses $2 \mathrm{a}$ and $2 \mathrm{~b}$. Instead, students who chose a supervisor because of similar research interests $(+4.2 \%)$ (Hypothesis 3 ) or because they were their supervisor at lower educational level $(+0.7 \%)$ are more satisfied.

\begin{tabular}{lccc}
\hline & $n$ & Professional relationship & Personal relationship \\
\hline Every day & $71(7 \%)$ & 5.31 & 4.75 \\
Several times a week & $254(27 \%)$ & 5.38 & 4.79 \\
Once a week & $280(30 \%)$ & 5.14 & 4.48 \\
Once in two weeks & $194(20 \%)$ & 5.13 & 4.51 \\
Once a month & $128(14 \%)$ & 5.15 & 4.51 \\
Once a semester & $20(2 \%)$ & 3.45 & 3.30
\end{tabular}

Ph.D. student's satisfaction with supervisors 


\section{HEED 15,1}

\section{2}

Table 2.

Regression models predicting Ph.D. students' satisfaction with their professional and personal relationship with their supervisor

\begin{tabular}{|c|c|c|c|c|c|c|c|c|}
\hline \multirow[b]{3}{*}{ (Intercept) } & \multicolumn{4}{|c|}{ Professional } & \multicolumn{4}{|c|}{ Personal } \\
\hline & \multirow{2}{*}{$\begin{array}{c}\text { Est } \\
4.11\end{array}$} & \multirow{2}{*}{$\frac{\mathrm{SE}}{0.26}$} & \multicolumn{2}{|c|}{ Sign } & \multirow{2}{*}{$\frac{\text { Est }}{4.08}$} & \multirow{2}{*}{$\frac{\mathrm{SE}}{0.35}$} & \multicolumn{2}{|c|}{ Sign } \\
\hline & & & $<2 \mathrm{e}-16$ & $* * *$ & & & $<2 \mathrm{e}-16$ & $* * *$ \\
\hline \multicolumn{9}{|l|}{ Interaction student-supervisor } \\
\hline $\begin{array}{l}\text { Freq. Meetings: Several times a week vs } \\
\text { everyday }\end{array}$ & -0.03 & 0.15 & 0.83 & & -0.07 & 0.20 & 0.74 & \\
\hline Freq. Meetings: Once a week vs everyday & -0.20 & 0.15 & 0.18 & & -0.36 & 0.20 & 0.08 & \\
\hline $\begin{array}{l}\text { Freq. Meetings: Once in two weeks vs } \\
\text { everyday }\end{array}$ & -0.39 & 0.16 & 0.02 & $*$ & -0.55 & 0.22 & 0.01 & $*$ \\
\hline Freq. Meetings: Once a month vs everyday & -0.45 & 0.18 & 0.01 & $*$ & -0.82 & 0.24 & 0.00 & $* * * *$ \\
\hline $\begin{array}{l}\text { Freq. Meetings: Once in a semester vs } \\
\text { everyday }\end{array}$ & -1.30 & 0.28 & 0.00 & $* * *$ & -1.45 & 0.38 & 0.00 & $* * *$ \\
\hline Gender Student-Supervisor: FM vs FF & -0.17 & 0.13 & 0.17 & & -0.02 & 0.17 & 0.93 & \\
\hline Gender Student-Supervisor: MF vs FF & -0.14 & 0.19 & 0.44 & & -0.13 & 0.25 & 0.61 & \\
\hline Gender Student-Supervisor: MM vs FF & -0.08 & 0.13 & 0.52 & & 0.09 & 0.17 & 0.62 & \\
\hline $\begin{array}{l}\text { Student and Supervisor-Same nationality: } \\
\text { yes }\end{array}$ & 0.08 & 0.09 & 0.38 & & -0.03 & 0.12 & 0.80 & \\
\hline Choice SP: similar research interests & 0.25 & 0.03 & 0.00 & $* * *$ & 0.10 & 0.04 & 0.01 & * \\
\hline Choice SP: same SP master & 0.05 & 0.02 & 0.01 & $* *$ & 0.05 & 0.02 & 0.02 & $*$ \\
\hline \multicolumn{9}{|l|}{ Characteristics of the supervisor } \\
\hline SP: Number of students supervised & -0.02 & 0.01 & 0.00 & $* * *$ & -0.02 & 0.01 & 0.08 & \\
\hline nt & 0.25 & 0.04 & 0.00 & *** & 0.17 & 0.05 & 0.00 & ** \\
\hline t Prof. vs Professor & 0.08 & 0.14 & 0.57 & & 0.15 & 0.19 & 0.44 & \\
\hline SP rank: Associate Prof. vs Professor & -0.05 & 0.09 & 0.58 & & -0.34 & 0.12 & 0.00 & $* *$ \\
\hline \multicolumn{9}{|l|}{ Characteristics of the student } \\
\hline & 0.17 & 0.04 & 0.00 & $* * *$ & 0.20 & 0.05 & 0.00 & $* * *$ \\
\hline ive and Executive & -0.05 & 0.04 & 0.17 & & 0.00 & 0.05 & 0.94 & \\
\hline ST: TS: Hiera & 0.16 & 0.04 & 0.00 & $* * *$ & 0.04 & 0.05 & 0.39 & \\
\hline ST: TS: Monarchic & 0.07 & 0.04 & 0.04 & $*$ & -0.01 & 0.05 & 0.80 & \\
\hline \multicolumn{9}{|l|}{ Context } \\
\hline Discipline: A & 0.27 & 0.34 & 0.43 & & 0.52 & 0.45 & 0.25 & \\
\hline line: Arts and sports vs Nat. Sciences & -0.04 & 0.47 & 0.93 & & 0.97 & 0.63 & 0.13 & \\
\hline scipline: Business vs Nat. Sciences & -0.20 & 0.40 & 0.62 & & 0.70 & 0.53 & 0.19 & \\
\hline Discipline: Computing vs Nat. Sciences & 0.12 & 0.22 & 0.60 & & -0.05 & 0.30 & 0.86 & \\
\hline Discipline: Education vs Nat. Sciences & 0.44 & 0.14 & 0.00 & $* *$ & 0.92 & 0.19 & 0.00 & $* * *$ \\
\hline e: Engineering vs Nat. Sciences & 0.11 & 0.11 & 0.31 & & 0.42 & 0.14 & 0.00 & ** \\
\hline Discipline: Humanities vs Nat. Sciences & 0.35 & 0.16 & 0.03 & * & 0.97 & 0.21 & 0.00 & $* * *$ \\
\hline Discipline: Medicine vs Nat. Sciences & -0.02 & 0.16 & 0.92 & & 0.42 & 0.22 & 0.06 & \\
\hline ne: Others vs Nat. Sciences & 0.11 & 0.23 & 0.64 & & 0.54 & 0.31 & 0.09 & \\
\hline Discipline: Social science vs Nat. Sciences & 0.34 & 0.13 & 0.01 & ** & 0.78 & 0.17 & 0.00 & \\
\hline Uni 1 vs Uni 2 & -0.30 & 0.10 & 0.00 & $* *$ & -0.29 & 0.13 & 0.03 & * \\
\hline Multiple $R^{2}(\%)$ & \multicolumn{4}{|c|}{32} & \multicolumn{4}{|c|}{17} \\
\hline \multicolumn{5}{|l|}{ Adjust } & \multicolumn{4}{|c|}{14} \\
\hline
\end{tabular}

Working under a supervisor with a larger number of Ph.D. students negatively affects students' satisfaction regarding their professional relationship $(-2.4 \%)$-even when considering the variable on the frequency of meetings, which suggests that having a larger number of Ph.D. students is likely to affect the length (and/or quality) of these meetings. A supervisor's involvement in research is a strong and significant predictor of professional relationship satisfaction $(+4 \%)$. Furthermore, students' thinking styles are important predictors of satisfaction. Type I TS have a positive effect, namely (1) legislative 
and liberal $(+2.7 \%)$ and $(2)$ hierarchical $(+2.5 \%)$. The monarchic style, that is, a preference for tasks that allow complete focus on one issue at a time, which is a type II TS, also has a moderate positive effect. Significant differences also exist in the satisfaction of students from different disciplines. Ph.D. students in education $(+6.1 \%)[8]$ and social sciences $(+5.1 \%)$ are more satisfied than Ph.D. students in the natural sciences, and Ph.D. students in arts and sports are the least satisfied $(-25.3 \%)$.

When it comes to personal relationships, students meeting once every two weeks or once in a month are significantly less satisfied than those meeting every day $(-9.3$ and $-13.6 \%)$, and those meeting only once in a semester are much less satisfied (-29.1\%) (Hypothesis 1 ). Students with a supervisor having the same gender or nationality are not more satisfied, which confutes Hypotheses $2 \mathrm{a}$ and $2 \mathrm{~b}$, whereas students who chose a supervisor because of similar research interests $(+1.5 \%)$ (Hypothesis 3 ) and because they were their supervision at a previous educational level $(+0.9 \%)$ are more satisfied of their personal relationship with the supervisor.

The number of $\mathrm{Ph} . \mathrm{D}$. students supervised does not affect satisfaction once the frequency of meetings variable is considered. A supervisor's involvement in the student's research is a predictor of personal satisfaction $(+2.6 \%)$. Ph.D. students supervised by associate professors are significantly less satisfied with their personal relationships than those supervised by full professors $(-5.8 \%)$. Ph.D. students with stronger legislative and liberal TS have better personal relationships with their supervisor $(+3.5 \%)$. Ph.D. students in the humanities $(+14.6 \%)$, education $(+13.6 \%)$, social sciences $(+11.3 \%)$ and engineering $(+6.6 \%)$ are more satisfied than Ph.D. students in the natural sciences.

The robust test using the sample of first- and second-year Ph.D. students provides very similar results to the main models [9]. It is important to remark that the supervisor's gender and age and the student's gender, academic year, age, number of children and parents' level of education are not significant predictors of satisfaction with personal or professional relationships, nor is the extent to which a Ph.D. student is supported by a scholarship, whether the Ph.D. student is a national or non-national citizen.

\section{Discussion and conclusion}

This study explored the factors affecting Ph.D. students' satisfaction with their personal and professional relationships with their supervisors at two East Asian universities, focusing on the characteristics of their interaction, as well as the supervisor's and student's traits, and the context.

The single most important predictor of personal and professional satisfaction with supervision is how frequently the student meets the supervisor. The results suggest that meeting at least one-time per week would be optimal, whereas meeting less frequently has a significant negative impact on satisfaction. In a similar vein, satisfaction with both personal and professional relationships decrease as the number of Ph.D. students under supervision increases. This is not only important for supervisee's satisfaction levels, as previous studies suggest it also leads to better research products (Barnes and Austin, 2009; $\mathrm{Li}$ and Seale, 2007). Supervisors need to be aware of the actual time necessary to develop a good relationship, when considering the number of Ph.D. students to supervise and estimating the time allotted to each supervision (Kimani, 2014). Our findings underline the importance of balancing the number of Ph.D. students an academic supervises with enough time for frequent meetings. Given the massification of Ph.D. programmes, supervisors and university administrators must be aware and manage the trade-off between quantity and quality, which is particularly critical when the quality of the doctorates is arguably on the decline and the pressures on Ph.D. students are mounting (Levecque et al., 2017).

Ph.D. student's satisfaction with supervisors 
HEED

15,1

A key finding is that satisfaction is not pre-determined by major demographic traits of the student, the supervisor nor their interaction. In fact, there are no differences in satisfaction according to the gender or age of the student, the supervisor, nor related to their interaction. Hence, for example, a female Ph.D. student supervised by a female supervisor is similarly satisfied as a female Ph.D. student supervised by a male supervisor (results that are aligned with Sosik and Godshalk's 2005, and Brown and Watson's 2010 findings). Moreover, it does not matter for satisfaction levels to have children or not, parents with a low or high educational background, a supervisor of the same nationality, a scholarship, and being a nonnational or national $\mathrm{Ph}$.D. student. Future research should explore whether in other contexts these variables do matter, and the reason thereof - such as how Ph.D. supervision is organized, the lack of specific support or cultural traits.

A supervisor's involvement in international research and having similar research interests are also important predictors of satisfaction, especially regarding the professional relationship. The discussion of how to match supervisee and supervisor has been a key concern in the literature on student satisfaction about the quality of supervision (e.g. Mainhard et al., 2009), and our results corroborate previous studies suggesting the importance of similar research interests (e.g. Gurr, 2001). The relevance of the supervisor's involvement in international research for student's satisfaction with supervision was not an unexpected finding, but still an important one for policy and practice. One could argue that this should not be a major concern for most academics in research-oriented universities since they tend to be internationally involved in research practices and communities, but it may become a key criterion for who should be able to supervise in non-research-intensive universities. If taken as an institutional criterion, some may think it would hinder junior academics from supervision. Yet nowadays most junior academics have considerable pre and postdoc research experience, and supervision represents for then an opportunity to improve their pedagogical skills, knowledge production and intellectual growth (Amundsen and McAlpine, 2011).

Ph.D. students that lean towards Type I thinking styles tend to be more satisfied with their supervisor. This finding has implications for the selection of Ph.D. students. For the last decade, scholars have pointed out that the number of $\mathrm{Ph}$.D. graduates has grown excessively, limiting their opportunities in the job market after graduation (Cyranoski et al., 2011; Gould, 2015) but also straining supervisors and the supervision process (Bøgelund, 2015). Arguably, the focus on Ph.D. student recruitment ought to be more stringent and aim to select students that prefer tasks requiring creativity and the ability to deal with abstraction and ambiguity (see McAlpine and Norton, 2006; Golde, 2000). Although this research is not measuring success, research has shown that satisfaction is associated with a good supervisory relationship that enables successful outcomes of the $\mathrm{PhD}$, and therefore, considering all dimensions that can contribute to this potential success should be envisaged when possible.

Last, but not least, the results show remarkable differences in satisfaction level of students in different disciplines. The fact that - all other conditions being the same-students in Social Sciences, Education and Humanities are more satisfied than students in Engineering and Natural Sciences may depend on differences on how work is organized and the goals of research, which in the latter fields is more oriented to projects. Future research should further explore the reasons underpinning such differences.

\section{Notes}

1. This is valid in structured doctoral programs since the role of informal learning, that is with the supervisor, is seen to be of much greater importance to the development of supervisor and candidate alike than the role of formal training, that is coursework (Amundsen and McAlpine, 2009; Hasrati, 2005). 
2. For the Hong Kong case, mainland Chinese and local students/supervisors are treated separately due to cultural, social and political differences, even though these groups share many socio-cultural attributes (see Yu and Zhang, 2016).

3. The original scale includes 65 items. As the GSS includes several items, a small sample was selected. Studies have found the 30-item sample to be reliable (Zhang et al., 2018)

4. For clarity, only those control variables that offered statistically significant results are included in the table. The full results are available upon request.

5. In the article, only the model including all the variables is shown. A table with all the models is available upon request

6. Namely that over time low/high satisfaction will lead to rarer/more frequent meetings.

7. In the survey, the value 5 means "true" in response to the statement: "I have good (. . .) relationship with my supervisor", while a 4 means "somewhat true". For a term of comparison, in a 0 to 10 scale, 5.17 equals 6.95 while 4.56 equals 5.93

8. Percentage refers to standardised beta coefficients - the full table is available upon request

9. Results are available upon request.

\section{References}

Amundsen, C. and McAlpine, L. (2009), "Learning supervision': trial by fire”, Innovations in Education and Teaching International, Vol. 46 No. 3, pp. 331-342.

Amundsen, C. and McAlpine, L. (2011), "New academics as supervisors: a steep learning curve with challenges, tensions and pleasures", in Amundsen, C. and McAlpine, L. (Eds), Doctoral Education: Research-Based Strategies for Doctoral Students, Supervisors and Administrators, Springer, Dordrecht, pp. 37-55.

Baker, V.L., Pifer, M.J. and Flemion, B. (2013), "Process challenges and learning-based interactions in stage 2 of doctoral education: implications from two applied social science fields", The Journal of Higher Education, Vol. 84 No. 4, pp. 449-476.

Barnes, B.J. and Austin, A.E. (2009), "The role of doctoral advisors: a look at advising from the advisor's perspective", Innovative Higher Education, Vol. 33 No. 5, pp. 297-315.

Bastalich, W. (2017), "Content and context in knowledge production: a critical review of doctoral supervision literature”, Studies in Higher Education, Vol. 42 No. 7, pp. 1145-1157.

Benmore, A. (2016), "Boundary management in doctoral supervision: how supervisors negotiate roles and role transitions throughout the supervisory journey", Studies in Higher Education, Vol. 41 No. 7, pp. 1251-1264.

Bøgelund, P. (2015), "How Supervisors perceive PhD supervision: and how they practice it", International Journal of Doctoral Studies, Vol. 10, pp. 39-55.

Brown, L. and Watson, P. (2010), "Understanding the experiences of female doctoral students", Journal of Further and Higher Education, Vol. 34 No. 3, pp. 385-404.

Carter, S., Blumenstein, M. and Cook, C. (2013), "Different for women? The challenges of doctoral studies”, Teaching in Higher Education, Vol. 18 No. 4, pp. 339-351.

Clark, B.R. (1983), The Higher Education System: Academic Organization in Cross-National Perspective, University of California Press, Berkeley.

Cyranoski, D., Gilbert, N., Ledford, H., Nayar, A. and Yahia, M. (2011), "Education: the PhD factory", Nature News, Vol. 472 No. 7343, pp. 276-279.

Deuchar, R. (2008), "Facilitator, director or critical friend? Contradiction and congruence in change and the social science PhD: supervisors' responses”, Teaching in Higher Education, Vol. 13 No. 4, pp. 489-500.
Ph.D. student's satisfaction with supervisors 
HEED 15,1

Fan, J.Q. and Zhang, L.F. (2014), "The role of learning environments in thinking styles", Educational Psychology, Vol. 34 No. 2, pp. 252-268.

Gardner, S.K. and Gopaul, B. (2012), "The part-time doctoral student experience", International Journal of Doctoral Studies, Vol. 7 No. 12, pp. 63-78.

Golde, C.M. (2000), "Should I stay or should I go? Student descriptions of the doctoral attrition process", The Review of Higher Education, Vol. 23 No. 2, pp. 199-227.

Gould, J. (2015), "How to build a better PhD”, Nature News, Vol. 528 No. 7580, p. 22.

Gu, J., Levin, J.S. and Luo, Y. (2018), "Reproducing 'academic successors' or cultivating 'versatile experts': influences of doctoral training on career expectations of Chinese $\mathrm{PhD}$ students", Higher Education, Vol. 76 No. 3, pp. 427-447.

Gurr, G.M. (2001), "Negotiating the 'rackety bridge' -A dynamic model for aligning supervisory style with research student development", Higher Education Research and Development, Vol. 20 No. 1, pp. 81-92.

Halbert, K. (2015), "Students' perceptions of a 'quality' advisory relationship", Quality in Higher Education, Vol. 21 No. 1, pp. 26-37.

Hasrati, M. (2005), "Legitimate peripheral participation and supervising PhD students", Studies in Higher Education, Vol. 30 No. 5, pp. 557-570.

Heath, T. (2002), “A quantitative analysis of $\mathrm{PhD}$ students' views of supervision”, Higher Education Research and Development, Vol. 21 No. 1, pp. 41-56.

Henrich, J. (2017), The Secret of Our Success: How Culture is Driving Human Evolution, Domesticating Our Species, and Making us Smarter, Princeton University Press, Princeton.

Hockey, J. (1994), "Establishing boundaries: problems and solutions in managing $\mathrm{PhD}$ supervisor's role", Cambridge Journal of Education, Vol. 24 No. 2, pp. 1-13.

Hockey, J. (1996), "A contractual solution to problems in the supervision of $\mathrm{PhD}$ degrees in the UK", Studies in Higher Education, Vol. 21 No. 3, pp. 359-371.

Holligan, C. (2005), "Fact and fiction: a case history of doctoral supervision", Educational Research, Vol. 47 No. 3, pp. 267-278.

Horta, H. and Santos, J.M. (2016), "The impact of publishing during the $\mathrm{PhD}$ on career research publication, visibility, and collaborations", Research in Higher Education, Vol. 57 No. 1, pp. $28-50$.

Horta, H., Cattaneo, M. and Meoli, M. (2019), "The impact of Ph.D. funding on time to Ph.D. completion", Research Evaluation, Vol. 28 No. 2, pp. 182-195.

Ives, G. and Rowley, G. (2005), "Supervisor selection or allocation and continuity of supervision: $\mathrm{PhD}$ students' progress and outcomes", Studies in Higher Education, Vol. 30 No. 5, pp. 535-555.

Jung, J. (2018), "Learning experience and perceived competencies of doctoral students in Hong Kong”, Asia Pacific Education Review, Vol. 19, pp. 187-198.

Jung, J., Horta, H., Zhang, L.-F. and Postiglione, G.A. (2021), "Factors fostering and hindering research collaboration with doctoral students among academics in Hong Kong", Higher Education. doi: 10.1007/s10734-020-00664-6.

Kaiser, H.F. (1960), "The application of electronic computers to factor analysis", Educational and Psychological Measurement, No. 20, pp. 141-151.

Kidman, J., Manathunga, C. and Cornforth, S. (2017), "Intercultural PhD supervision: exploring the hidden curriculum in a social science faculty doctoral programme", Higher Education Research and Development, Vol. 36 No. 6, pp. 1208-1221.

Kimani, E.N. (2014), "Challenges in quality control for postgraduate supervision”, International Journal of Humanities Social Sciences and Education, Vol. 1 No. 9, pp. 63-70.

Kinzler, K.D., Corriveau, K.H. and Harris, P.L. (2011), "Children's selective trust in native-accented speakers", Developmental Science, Vol. 14 No. 1, pp. 106-111. 
Koberg, C.S., Boss, R.W. and Goodman, E. (1998), "Factors and outcomes associated with mentoring among health-care professionals", Journal of Vocational Behavior, Vol. 53 No. 1, pp. 58-72.

Kram, K.E. (1986), "Mentoring in the workplace", in Hall, D.E. and Associates (Eds), Career Development in Organizations, San Francisco CA Jossey-Bass, pp. 160-201.

Kurtz-Costes, B., Helmke, L.A. and Ülkü-Steiner, B. (2006), "Gender and doctoral studies: the perceptions of Ph.D. students in an American university", Gender and Education, Vol. 18 No. 2, pp. 137-155.

Kwan, B.S.C. (2013), "Facilitating novice researchers in project publishing during the doctoral years and beyond: a Hong Kong-based study", Studies in Higher Education, Vol. 38 No. 2, pp. 207-225.

Laufer, M. and Gorup, M. (2019), "The invisible others: stories of international doctoral student dropout", Higher Education, Vol. 78, pp. 165-181.

Lee, A. (2008), "How are doctoral students supervised? Concepts of doctoral research supervision", Studies in Higher Education, Vol. 33 No. 3, pp. 267-281.

Levecque, K., Anseel, F., De Beuckelaer, A., Van der Heyden, J. and Gisle, L. (2017), "Work organization and mental health problems in PhD students", Research Policy, Vol. 46 No. 4, pp. 868-879.

Li, S. and Seale, C. (2007), "Managing criticism in PhD supervision: a qualitative case study", Studies in Higher Education, Vol. 32 No. 4, pp. 511-526.

Lindsay, S. (2015), "What works for doctoral students in completing their thesis?", Teaching in Higher Education, Vol. 20 No. 2, pp. 183-196.

Mainhard, T., van der Rijst, R., van Tartwijk, J. and Wubbels, T. (2009), "A model for the supervisordoctoral student relationship”, Higher Education, Vol. 58 No. 3, pp. 359-373.

Maloshonok, N. and Terentev, E. (2019), "National barriers to the completion of doctoral programs at Russian universities", Higher Education, Vol. 77, pp. 195-211.

Manathunga, C., Pitt, R. and Critchley, C. (2009), "Graduate attribute development and employment outcomes: tracking $\mathrm{PhD}$ graduates", Assessment and Evaluation in Higher Education, Vol. 34 No. 1, pp. 91-103.

McAlpine, L. and Norton, J. (2006), "Reframing out approach to doctoral programs: an integrative framework for action and research", Higher Education Research and Development, Vol. 25 No. 1, pp. 3-17.

McAlpine, L., Paulson, J., Gonsalves, A. and Jazvac-Martek, M. (2012), "Untold doctoral stories: can we move beyond cultural narratives of neglect?", Higher Education Research and Development, Vol. 31 No. 4, pp. 511-523.

McCallin, A. and Nayar, S. (2012), "Postgraduate research supervision: a critical review of current practice", Teaching in Higher Education, Vol. 17 No. 1, pp. 63-74.

Mowbray, S. and Halse, C. (2010), "The purpose of the PhD: theorizing the skills acquired by students", Higher Education Research and Development, Vol. 29 No. 6, pp. 653-664.

Norman, G. (2010), "Likert scales, levels of measurement and the 'laws' of statistics", Teaching in Higher Education, Vol. 15, pp. 625-632.

Ooms, W., Werker, C. and Hopp, C. (2019), "Moving up the ladder: heterogeneity influencing academic careers through research orientation, gender, and mentors", Studies in Higher Education, Vol. 44 No. 7, pp. 1268-1289.

Pásztor, A. and Wakeling, P. (2018), "All PhDs are equal but. . .institutional and social stratification in access to the doctorate", British Journal of Sociology of Education, Vol. 39 No. 7, pp. 982-997.

Pearson, M., Evans, T. and Macauley, P. (2008), "Growth and diversity in doctoral education: assessing the Australian experience", Higher Education, Vol. 55 No. 3, pp. 357-372.

Roach, M. and Sauermann, H. (2019), "The declining interest in an academic career", PLoS ONE, Vol. 12 No. 9, p. e0184130, doi: 10.1371/journal.pone.0184130.

Ph.D. student's satisfaction with supervisors 
HEED

15,1

Shen, W., Gao, Y. and Zhao, S. (2018), "Single-advisor system or joint advisor system: the preference and satisfaction of $\mathrm{PhD}$ students for different supervision models", Chinese Education and Society, Vol. 51 No. 3, pp. 222-231.

Shibayama, S. (2019), "Sustainable development of science and scientists: academic training in life science labs", Research Policy, Vol. 48 No. 3, pp. 676-692.

Shin, J.C., Postiglione, G.A., Ho, K.C., Horta, H., Zhang, L.F., Kim, E. and Kim, S.J. (2015), Graduate Students Survey, Unpublished thesis, Seoul National University, Seoul.

Shin, J.C., Kim, S.J., Kim, E. and Lim, H. (2018), "Doctoral students' satisfaction in a research-focused Korean university: socio-environmental and motivational factors”, Asia Pacific Education Review, Vol. 19, pp. 159-168.

Sosik, J.J. and Godshalk, V.M. (2000), “The role of gender in mentoring: implications for diversified and homogeneous mentoring relationships", Journal of Vocational Behavior, Vol. 57 No. 1, pp. 102-122.

Sosik, J.J. and Godshalk, V.M. (2005), "Examining gender similarity and mentor's supervisory status in mentoring relationships”, Mentoring and Tutoring: Partnership in Learning, Vol. 13 No. 1, pp. 39-52.

Sternberg, R.J., Wagner, R.K. and Zhang, L.F. (2007), Thinking Styles Inventory - Revised II, Tufts University, Medford, MA, Unpublished test.

Torka, M. (2018), "Projectification of doctoral training? How research fields respond to a new funding regime”, Minerva, Vol. 56, pp. 59-83.

Vassil, K. and Solvak, M. (2012), "When failing is the only option: explaining the failure to finish PhDs in Estonia”, Higher Education, Vol. 64 No. 4, pp. 503-516.

Whitley, R. (2000), The Intellectual and Social Organization of the Sciences, Oxford University Press , Oxford.

Wisker, G. (2005), The Good Supervisor, Macmillan, Palgrave.

Yu, B. and Zhang, K. (2016), “It's more foreign than a foreign country': adaptation and experience of mainland Chinese students in Hong Kong”, Tertiary Education and Management, Vol. 22 No. 4, pp. 300-315.

Zhang, L.F., Horta, H., Jung, J., Chen, G. and Postiglione, G. (2018), "The role of thinking styles in program satisfaction and perceived intellectual competence among STEM doctoral students", Journal of Educational Psychology, Vol. 111 No. 4, pp. 573-589.

Zhao, C.M., Golde, C.M. and McCormick, A.C. (2007), "More than a signature: how advisor choice and advisor behaviour affect doctoral student satisfaction", Journal of Further and Higher Education, Vol. 31 No. 3, pp. 263-281.

\section{Corresponding author}

Hugo Horta can be contacted at: horta@hku.hk

For instructions on how to order reprints of this article, please visit our website:

www.emeraldgrouppublishing.com/licensing/reprints.htm

Or contact us for further details: permissions@emeraldinsight.com 